\title{
The cultivation of students' social adaptation ability in the physical education of higher vocational college
}

\author{
Jie $\mathrm{Xu}$
}

JiangXi Technical College of Manufacturing

Keywords: Physical education of higher vocational college; Social adaptation; Ability cultivation

\begin{abstract}
It is the duty of higher vocational colleges to develop the students' ability of social adaptation. As a part of the higher vocational education, physical education has the function that the other disciplines can't replace in cultivating students' social adaptation ability. From the necessity of cultivating students' social adaptation ability in physical education, this paper expounds the specific function and approach of physical education in cultivating and improving students' ability of social adaptation.
\end{abstract}

\section{Introduction}

Social adaptation ability refers to the integration of the relatively stable characteristics of individuals in the process of socialization. One can survive in the competitive social environment only when he learns, improves and depend on his social adaptation ability. If he cannot adapt to society, what he has to face is to be eliminated by the society.

In the process of establishing the socialist market economic system, the talent demand standard of economic construction and social development is inter-disciplinary, on the basis of qualified physical and mental health, good social adaptability and personality and strong creativity and competitiveness. To this end, the ministry of education promulgated the "National Ordinary Higher School Physical Education Curriculum Teaching Guidelines" and stipulated social adaptation as one of the main learning purposes. Higher vocational education occupies very important position in our country's education career, and the improvement of higher vocational education can promote the progress of the overall level of education in our country. The current education in China is facing a grim situation of reform, the most important of which is the reform of the higher vocational education. Cultivating students' social adaptation ability is one of the important tasks of education reform. At the same time, it is also one of the responsibilities of the higher vocational colleges.

The teaching activities in physical education are generally made up of specific circumstance. It should be noticed that the circumstance is not accidental, but specially built, and is a simplified and concentrated form of society. In the process of physical education, the interaction among teachers and students, or students and students, can strengthen students' ability to adapt in different scenarios, which will be conducive to the cultivation of the students' ability to adapt to the society. Due to the influence of the exam-oriented education for many years, there is a larger and larger gap between college students' social adaptation ability and the demand of modern society. Especially in the rapid development of social economy in modern times, the content that social adaptation ability contains is widespread, and there is no unified conclusion to students' social adaptation ability. As a matter of course, it is of great significance to conduct a research on the cultivation of students' social adaptation ability through physical education of higher vocational colleges. 


\section{The necessity of cultivating students' social adaptation ability in physical education of higher vocational colleges.}

1. Social adaptation is the inevitable requirement of economy development

(1)Social adaptation reflects the particularity of higher vocational college development. Higher vocational college is a new kind of product at the end of 20th century and is also the need of the development of times. The predecessor of higher vocational college is advanced from technical secondary school or merged by a few vocational schools. As a matter of course, teachers' theoretical level and scientific research ability are relatively weaker than colleges and universities. In aspects of education mode and management system, it is deeply influenced by its predecessor, technical secondary school. However, it has experienced 10 years of breeding in the active transformation of concept and role, higher vocational college has gradually adapted to the need of modern education and kept up with the pace of times. The teaching of physical education has basically been in conformity to the subjective idea of "National Ordinary Higher School Physical Education Curriculum Teaching Guidelines”, that is, to achieve three-dimensional health, physical health, mental health and the all-round development of social adaptation, through physical education.

(2)The cultivation of students' ability to adapt is the need of existence and development of higher vocational colleges.

The quality of the students is the symbol and sign of the school's image, which can reflect the teaching level and social prestige of the school. In the case of an increasingly competitive society, students become the best advertisement of school recruitment. The students in higher vocational colleges are mostly practical talents and work as blue-collars after graduation from school. The enterprises hope students can adapt to working environment as soon as possible and assume that students can adapt to the enterprise as quickly as possible, thus, they are able to be identified and accepted by the enterprise. So, students' social adaptation ability relates to the survival and development of higher vocational colleges.

2. Social adaptation is one of the learning purposes of higher vocational education

(1) It is the basic task of education to develop the students' ability to adapt. People's development cannot be separated from education and the fundamental task of education is to cultivate talents to adapt to the social development. In "The central committee and state council's decision on deepening education reform and comprehensive promotion of quality education”, clear requirements have been put forward for all kinds of education at all levels to strengthen the students' ability development, which is referred to an unprecedented height in reform of education in our country. Facing the challenges of the 21st century, it is the urgent need of the current economic and social development to strengthen students' ability cultivation and promote the education teaching reform. Social adaptation ability is the basic requirement of the society for people, an important aspect of the development level of people and the society's subjective demand to individual in society survival and development. Therefore, to cultivate the students' ability of social adaptation is the basic task of education.

(2)It is the educational goal of higher vocational education to develop students' ability to adapt to society. The cultivation target of higher vocational colleges is to cultivate practical talents that can meet the needs of modernization and have certain practical professional skills. On the cultivation goal, the professional and practical characteristics should be more highlighted. The physical education of higher vocational college must be closely focused on the goal of cultivation. Higher vocational college students, in order to set up a clear professional direction after entering school, need to select specialty according to the characteristics of teaching content, make full use of the advantage of physical education and improve their quality and physical agility according to the 
characteristics of various professional practice. Therefore, they are able to be better qualified for the professional work after graduation. In the cultivation target, physical education of higher vocational colleges will present a unique advantage.

(3)The particularity of higher vocational college students determines the necessity of cultivating students' social adaptation ability. Multi-level vocational college students determine the teaching plan of physical education to be adjusted according to different stages of students. Generally speaking, higher vocational college students have relatively poor cultural basis and weak self-study ability, self-control ability, frustration resistance ability and endurance ability. It will be difficult for them to adapt to the rapidly changing society if not systematically cultivated.

3. Students' social adaptation ability is not innate, but forms after a long period of cultivation in process of physical education. It is the essential difference between man and animals whether to cultivate social adaptation ability by means of education. As a kind of education activity, physical education has its special function in cultivating students' ability of social adaptation.

(1)Physical education helps to cultivate the students' team cohesion. A team that only has the cohesive force has the execution, effect and performance accordingly. The higher the cohesion of a group is, the higher the efficiency of the team activities is. The team members attract each other, commit to team activities with full heart and strive to achieve the goal of the team with other members. From the perspective of the demand of enterprise, team spirit and cooperation consciousness is valued by all kinds of enterprises. In the process of physical education, physical activities more is conducted by a group, especially in the competition. So, what it all needs is collective and mutual cooperation. It helps to cultivate students' team cohesion, group consciousness and cooperation ability.

(2)Physical education helps to cultivate students' ability of interpersonal communication. In the process of physical education, whether it is physical course or extracurricular physical education activities, teachers and students should interact and communicate with each other. Most of physical education activities are organized in groups, in which interpersonal interaction conducted in an open environment is very frequent, so it can promote the communication and exchange of students. Students can establish a friendly relationship in the atmosphere of mutual learning, cooperation and competition, enhance the emotional experience of interpersonal communication and cultivate the consciousness and the ability of harmony with others. So, physical education activities play an irreplaceable special role to in cultivating students' interpersonal skills.

(3)Physical education helps to cultivate students' ability to withstand setbacks. Modern society is a competitive society with rapid social change, so setbacks in work and life are inevitable, which usually lead to physical and mental strike to different degree, thus affect a person's mood and normal rhythm of life. There will also be competition in sports, in which success and failure are unavoidable, so, it is a good chance for students to face the failure in the process physical education. Bearing setbacks is a process of psychological adjustment, which helps to improve the ability of social adaptation. The ability to withstand setbacks is an important aspect of social adaptation. Through physical education, students' ability to overcome the difficulties in adversity can be largely improved, which lays a good foundation for them to better adapt to the complex social environment in the future.

(4)Physical education helps to cultivate students' willpower. The process of physical teaching is mostly in the outdoor. In such special learning environment, students must pay great efforts to a variety of physical activities, whether it is running, jumping, throwing or climbing. To achieve a certain goal or complete a task, they must shoulder high load with indomitable willpower. The completion of each task or every progress will give rise to their strong or subtle emotional 
experience, so as to gain self-esteem and confidence. Therefore, students' willpower can be strengthened and the spirit and quality to bear hardships and stand hard work can be improved as well.

(5)Physical education helps to develop students' consciousness of specification and improve their ability of self-control and self-discipline. The standard and criterion in physical competition specifies the conditions of the contestants and restrict the behavior of the participants. The classroom routine in physical education, including all kinds of collective activities, games and competitions, has its specific rules and requirements, so each participant is to obey the rules and use rules to restrain their own behavior. If in violation of the rules, they will get the corresponding punishment. Therefore, in the competition, the rule is an invisible force to constrain them, which can improve their ability of self-control and self-discipline. The consciousness to comply with the rules will gradually migrate to the students' daily life, which contributes to their future life in the society and lays a good foundation for them to participate in social competition and observe various social rules and regulations.

\section{Specific measures of cultivating students' ability of social adaptation in the physical education of higher vocational colleges}

1. Reasonable arrangement of teaching content according to students' vocational characteristics

Physical education of higher vocational colleges should constantly arrange and update the physical education courses according to the development of the society and make the school teaching always maintain close ties with the need of the society. The selection of teaching content aims to make students more quickly adapt to the society in accordance with the students' course selection and their own characteristics. At the same time, the teaching content must be combined with professional features, help restore students' physical ability, improve students' ability to survive the project, break through the original curriculum structure and change the monotonous type of physical education.

In teaching arrangement, foundation courses of physical education can be established in the fresh year, aiming to improve the enthusiasm of students to participate in sports, maximize students' creativity, strengthen the guidance in students' learning method and practice methods and improve students' ability of self-study in practice. In the sophomore year, optional courses are students-oriented, follow higher vocational college students' physical and mental development and interests, actively adapt to the needs of students' personality development. In junior year, optional course should be established in the guidance of teaching target, teaching content and teaching time, so as to help students develop their skills and inspire their learning interests and enthusiasm.

2. Create a miniature society and cultivate students' social consciousness

Physical education to some extent is a microcosm of a miniature society, where there are cooperation and competition, opportunities and challenges, and success and failure. Each person plays a different role in this mini society, forms a team and become a partner with the people they are not familiar with anytime and anywhere. May at any time will partner evolved into the competition. They can be a participant, competitor, partner and fighter, and also can be a referee, athlete and coach. In physical education competition, they can play different role at any time, adapt to their own role, adapt to different task environment at any time. In this way, students' cooperation ability, communication ability and flexibility ability can be improved, which provides a platform for creating conditions to improve the students' social adaptation ability.

3. Pay attention to hone the will of the students, improve the social adaptation ability

In any physical activity, students will undergo a double burden on both body and mind. Physical 
activity of each time plays a major role in cultivating students' strong will and honing students' perseverance. So, in the physical education of higher vocational colleges, must increase students can hone the will of the content. Teachers in the teaching process must pay attention to the guide for students, so as to improve the students' social ability. For example, in the process of physical education of higher vocational colleges, teachers always pay attention to students' mood changes when students show negative emotions, and timely give them encouragement and help them realize the importance of tenacity, so that students can improve the ability to adapt to society in the hone.

\section{Conclusion}

With the further development and perfection of Chinese higher vocational education, higher vocational students' comprehensive quality has attracted extensive attention of society, especially higher vocational students' outlook of life, world and value, response to the heavy study pressure and employment pressure, etc. Higher vocational colleges need to make an effective and positive guidance in their social adaptation.

Physical education in higher vocational college needs to constantly advance with times, blaze new trails and cultivate practical talents so as to enable them to improve their social adaptation ability and fit with the time spirit and social progress. According to the needs of social development and the characteristics of students' body and mind, physical education of higher vocational colleges should accurately grasp the different types and levels of higher vocational students' ideas, psychological characteristics and differences. In reference to physical education teaching experience, life philosophy and humanities spirit, it is necessary for higher vocational colleges to guide and help students to establish correct and healthy outlook of value, establish the basic principle of life and improve the ability of social adaptation to serve the society.

School education is a place for social interaction, so, the teaching effect of physical education on students' formation and development of social adaptation ability can't be replaced by the other disciplines. Continuous exploration and practice on the influence of physical education teaching activities on students' growth can give full play to its special functions in the cultivation of social adaptation ability and adapt to the new requirements of the various types of senior specialized talents cultivation in the knowledge and economy era of the 21st century, so as to better achieve the teaching objectives of higher vocational education.

\section{References}

[1]Min Guihua. Students' social adaptation ability training strategy in higher vocational school[J]. Contemporary Sports Technology, 2014 (14): 70-71.

[2]Dang Weiguo. The cultivation of students' social adaptation ability in Physical education teaching[J]. Bulletin of Sport Science \& Technology, 2012, 13 (3): 10-11.

[3]Gu Xiaoxue. The influence of sports and health research on middle school students' social adaptation abilit [D]. East China Normal University master’s thesis, 2006. 